\title{
Modified Bhramari Pranayama in Covid 19 Infection
}

\author{
M. K. Taneja ${ }^{1}$ (D)
}

Received: 4 May 2020/Accepted: 9 May 2020/Published online: 20 May 2020

(C) Association of Otolaryngologists of India 2020

\begin{abstract}
The Coronavirus (2019-Cov-2) infection Covid19 is highly contagious caused by single stranded RNA virus (+ssRNA) with nucleocapsid and spreading widely all across the world and responsible for more than 3.6 million morbidity and 0.25 million mortality No specific treatment is available till date. The clinical symptoms are mainly upper respiratory leading to diffuse viral pneumonia and multiple organ failure involving. Kidney, Liver and Heart along with coagulopathies. During 2004 (SARS$\mathrm{CoV})$ pandemic role of nitric oxide in its management is well demonstrated. Nitric Oxide (NO) reversed pulmonary hypertension. Improved severe hypoxia and shortened the stay in ICU and ventilatory support. Nitric Oxide increased the survival rate. The genetic composition of Corona Virus (SARS-CoV) is almost similar to Covid-19, thus indicates good chances of effectiveness or enhancement in results by Nitric Oxide along with other modes in treatment of Covid19. It has been proved by studies by serendipity humming increases NO Expression dramatically.It is estimated that humming increases the endogenous generation of nitric oxide level by 15 -fold. Hypoxia in ARD Syndrome leads to blood coagulation by depression of body defence anticoagulatory and fibrolytic properties along with metabolic acidosis. If we go into hypoxic hypercapnic state no hyper coagulation takes place. Hence Bhramari by enhancing the expression of Nitric Oxide and increased Carbon dioxide by extended exhalation and alkaline $\mathrm{pH}$ prevents coagulopathies and morbidity due to Covid-19.
\end{abstract}

M. K. Taneja

tanejaentcenter@gmail.com

1 Indian Institute of Ear Diseases, E-982, C.R.Park, New Delhi, India
Keywords Covid-19 - Coronavirus (SARS-CoV-2) . Nitric oxide - Bhramari Pranayam - Metabolic . Acidosis $\cdot \mathrm{pH} \cdot$ Coagulopathies $\cdot$ RNA respiratory VIRUS . Ginger $\cdot$ Liquorice $\cdot$ Cinnamon

The Coronavirus (2019-Cov) infection Covid-19 is highly contagious caused by single stranded RNA virus (+ssRNA) with nucleocapsid and spreading widely all across the world and responsible for more than 3.6 million morbidity and 0.25 million mortality (COV) is a crown like appearance as the name derives from latin "Coronam" termed crown, due to presence of spikes glycoprotein on the envelope. No specific treatment is available till date and even etiopathology is a matter of research. The clinical symptoms are mainly upper respiratory leading to diffuse viral pneumonia and multiple organ failure involving. Kidney, Liver and Heart along with coagulopathies. Reported fatality is around 32.0 /million-while mortality in ICU patients has reached upto 63\%. During 2004 (SARS-CoV) pandemic role of nitric oxide in its management is well demonstrated [1]. Nitric Oxide (NO) reversed pulmonary hypertension. Improved severe hypoxia and shortened the stay in ICU and ventilatory support. Nitric Oxide increased the survival rate. The genetic composition of Corona Virus (SARS-CoV) is almost similar to Covid-19, thus indicates good chances of effectiveness or enhancement in results by Nitric Oxide along with other modes in treatment of Covid-19 [2].

As discussed earlier nitric oxide inhibits viral protein and RNA. It has been observed that Nitric Oxide Synthase reduces the yield of progeny virus by $82 \%$ thus by virtue of its anti viral effect reduces the replication of corona virus [3]. 
Nitric Oxide may also stimulate ciliary motility [4] inhaled NO therapy is clinically approved in new born children with persistent pulmonary hypertension [5].

It has been proved by studies by serendipity humming increases NO Expression dramatically [6]. This is as a consequence of oscillating sound wave and affecting air exchange in the sinus. The gas exchanges in the sinus by humming in every single exhalation while it takes $5 \mathrm{~min}$ to $30 \mathrm{~min}$ in quite breathing for exchange of air in sinuses. We can conclude that NO acts like aaerocrine hormone to enhance pulmonary vascular resistance.

Nitric oxide is a gas molecule which has become an exceptionally important molecule in biophysics. It is a key biological messenger playing an important role in various biological processes at the cellular level. Nitric oxide is known as endothelium-derived relaxing factor and is biosynthesized endogenously from semi-essential amino acid, L-argenine, molecular oxygen, and various nitric oxide synthase enzymes [7]. Nitric oxide is anti inflammatory and contributes to nonspecific host defence against bacterial, viral, fungal, parasitic infections, hence takes care of infection in the body. Nitric oxide improves ventilation-perfusion ratio in the lung along with relaxation of bronchial tree smooth muscles, hence oxygen uptake is increased and provides relief in bronchial asthma.

Humming increases the production of nitric oxide. Eby explained humming as a sonic cleanser, cures the infection of respiratory tract. Humming exercise also increases the vital capacity. It is estimated that humming increases the endogenous generation of nitric oxide level by 15 -fold as compared with the quite exhalation [8]. Hypoxia in ARD Syndrome leads to blood coagulation by depression of body defence anticoagulatory and fibrolytic properties along with metabolic acidosis. If we go into hypoxic hypercapnic state no hyper coagulation takes place. The metabolic acidosis/acidic $\mathrm{pH}$ enhances the clot formation by $168 \%$ just by lowering the $\mathrm{pH}$ to 6.8 and further aggravate the coagulopathies.

Hence Bhramari by enhancing the expression of Nitric Oxide and increased Carbon dioxide by extended exhalation and alkaline $\mathrm{pH}$ prevents coagulopathies and morbidity due to Covid-19.

\section{Alkaline diet}

Honey /dates/pine apple juice /sprout and raw leafy green vegetables added to diet boost the immune system.

Foods to enhance Nitric Oxide expression (rich in dietary nitrates, which body can convert to nitric oxide).

1. Beets. 2. Garlic. 3. Meat. 4. Dark Chocolate. 5. Leafy Greens. 6. Citrus Fruits. 7. Pomegranate. 8. Nuts and Seeds. 9. watermalon. 10 Redwine. Addition of beet root in non-diabetics and neem in diabetics may be considered in selective cases. All patients on anti hypertensive may be supplemented with rock salt and relaxation therapy.

Antiviral herbs Ginger, Liquorice, Cinnamon garlic may be added if project permits. The structure of coronavirus is composed of RNA based protein that contains amino ($\mathrm{NH}_{2}$ ) and Carboxyl (-COOH) it includes nucleocapsid protein (N-Protein) spike protein (S-Protein) and affects the gastrointestinal tract and damage other organs. It has been observed plant extract of hydroxyl group $(-\mathrm{OH})$ chemically deactivate the active component of virus by esterification process. Licorice (Glycerrhiza globra) can be added as supplement in holistic management [9].

\section{Ginger}

Zingiber Officinale contains gingerols, paradols, sesquiterpenes, shogaols having anti-inflammatory and antioxidant properties and have shown to be protective in human respiratory syncytial virus (CHRVS). Thus ginger as herbel food can be considered to enhance immune power [10]. All the patients should be checked for deficiency of Vit D and corrected [11].

\section{Technique}

Patient is instructed to take a slow deep abdominal breath, lift the tongue and press on hard palate in Khechari Mudra, hold the breath in, blow the cheek for better echo, close both ears with thumbs of both hands keeping them on concha simultaneously blocking the ears, and both eyes are gently closed by index finger. The tip of index finger should rest on the lateral wall of nose. Both middle fingers are put on base of ala of nose. Mouth is closed on both sides, upper lip by ring fingers and lower lip by little fingers. Both eyes are focused in Shambhavi drishti at the Ajna Chakra in between both eyebrows. A constant rhythmic uninterrupted specific frequency sound (mouth closed jaw relaxed) is generated. Spiritual concentration is focused on DwarikaDhish (Deity). During humming command is given that whole body is getting charged and you are full of energy. Visualise and feel the energy. After complete exhalation, hold the breath out; Vahya Kumbhak is enforced and spiritual focus on Lord Shiva (Deity). Keep holding the breath out as long as possible, simultaneously give a command to brain that my whole body is revitalizing. I am relaxed, I am healthy, I am happy and feel the happiness and wellness along with increase vitality. The exercise can be performed sitting comfortably in calm place, eyes closed, relaxed mood with a smile on face, A high pitch sound gives better results. For better result, 
whole body, mind and soul should be relaxed eyes are gently closed. You should be able to visualise a faint dusty brown light at solar plexes (Ajna Chakra) matching with the colour of pineal gland. After completing the bhramari hold the breath out for maximum comfortable duration. This optimizes the $\mathrm{CO}_{2}$ level in blood, tissue and cellular level enhancing $\mathrm{HCO}_{3}$ anion leading to apoptosis and revitalization $[12,13]$.

\section{Conclusion}

The proposed hypothesis is based on the principal of physiology of Nitric Oxide, Carbon dioxide and $\mathrm{pH}$ of body. Giving a command and its visualization in relaxed phase (alpha brain wave state leads) to release of feel good hormones lowers the cortisol level. It leads to enhance immune response, physiological healing and over all wellness.

Acknowledgement I accept to undertake all the responsibility for authorship during the submission and review stages of the manuscript. No financial support was received in the preparation of this article.

\section{Compliance with Ethical Standards}

Conflict of interest The authors declare that they have no conflict of interest.

Ethical approval This article does not contain any studies with human participants or animals performed by any of the authors.

\section{References}

1. Akerstrom S, Mousavi-Jazi M, Klingstrom J, Leijon M, Lundkvist A, Mirazimi A (2005) Nitric oxid inhibits the replication cycle of severe acute respiratory syndrome coronavirus. J Virol 79:1966-1969. https://doi.org/10.1128/JVI.79.3.1966-1969.2005

2. https://clinicaltrials.gov/C+2/result, NIH U.S. National Library of Medicine Nitrous Oxide inhalation for severe acute respiratory syndrome in Covid-19 (NOSARSCOVID).

3. Cinatl J, Morgenstern B, Bauer G, Chandra P, Rabenau H, Doerr HW (2003) Treatment of SARS with human interferons. Lancet 362:293-294

4. Jain B, Rubinstein I, Robbins RA, Leise KL, Sisson JH (1993) Modulation of air way Epithelial cell ciliary beat frequency by nitric oxide. Biochem Biophys Commun 191:83-86

5. Robbert DJ Jr, Fineman JR, Morin FC, 3rd Sahul PW, Rimer S (1997) Inhaled nitric oxide and persistent pulmonary hypertension of the new born. The inhaled nitric oxide study group. New Engl J Med 336:605-610

6. Weitzberg E, Lundberg JO (2002) Humming greatly increases nasal nitric oxide. Am J Respir Crit Care Med 166:144-145

7. Taneja MK (2016) Nitric oxide BhramariPranayam, and deafness. Indian J Otol 22:1-3. Available from https://www.youtube/ 9rOnhM_WO6s.

8. Eby GA (2006) Strong humming for one hour daily to terminate chronic rhinosinusitis in four days: a case report and hypothesis for action by stimulation of endogenous nasal nitric oxide production. Med Hypotheses 66:351-354

9. Chang JS, Wang KC, Yeh CF, Shieh DE, Chiang LC (2013) Fresh ginger (Zingiber Officinale) has anti-viral activity against human respiratory syncytial virus in human respiratory tract cell lines. J Ethnopharmacol 145(1):146-151

10. Brochot A, Guilbot A, Haddioui L, Roques C (2017) Antibacterial, antifungal, and antiviral effects of three essential oil blends. Microbiologyopen. 6(4):e00459

11. Taneja MK, Taneja V (2013) Vitamin D, Deficiency in E.N.T. Patients. Indian J Otolaryngol Head Neck Surg 13(55):57-60

12. Taneja MK Prevention and rehabilitation of old age deafness. Indian Journal of Otolaryngology \& HNS, online published $04 / 16 / 2020$.

13. Taneja MK (2015) Improving hearing performance through yoga. J Yoga Phys Ther 3:194. https://doi.org/10.4172/2157-7595. 1000194

Publisher's Note Springer Nature remains neutral with regard to jurisdictional claims in published maps and institutional affiliations. 